\title{
Hypertension among Young Adults in the Shopping Malls of Kathmandu
}

\author{
Shakya S, Timilsina M, Timilsina K, Lamsal M, Dhakal S, Neupane P
}

\section{Abstract \\ Background}

Hypertension is a major public health challenge in the world. Developing countries share the major burden of it. Unlike thought before, hypertension is increasing among poor, young and women.

\section{Methods}

It was a cross sectional study carried out in The Hypertension Screening and Awareness Program conducted in the shopping malls at the heart of Kathmandu on the occasion of World Hypertension Day 2012 by Shahid Gangalal National Heart Center, Kathmandu.

The blood pressure was measured according to World Heart Organization's guideline by registered nurses. There were total 486 participants with the mean age of $29.51 \pm 10.77$ years. Majority of the participants were male (67.1\%). Most of the participants were less or equal to 40 years (84.6\%). Mean systolic blood pressure was $112.3 \pm 14.69 \mathrm{mmHg}$ and mean diastolic blood pressure was $75.09 \pm 11.89$ $\mathrm{mmHg}$. Average mean blood pressure was $87.41 \pm 12.28 \mathrm{mmHg}$ in the study population.

\section{Results}

Despite majority of participants were at young age, prevalence of hypertension was $23.7 \%$, pre-hypertension was $30 \%$ and $46.3 \%$ had ideal blood pressure according to JNC-7 Classification. Prevalence of hypertension was higher among male (30.39\% vs. 10\%). Almost two third of the hypertensive subjects were less or equal to 40 years (64.35\%). Awareness, treatment and control of hypertension were $39.13 \%, 18.26 \%$ and $7.38 \%$ respectively.

\section{Conclusion}

In conclusion, Hypertension is an emerging public health challenge in urban areas of Nepal. Most importantly, it may be increasing among young population. Moreover, awareness, treatment and control rates are not satisfactory.

Key Words Hypertension, Prevalence, Awareness, Treatment, Control, Shopping Malls, Screening 


\section{Introduction}

There are at least 970 million people worldwide with elevated blood pressure. About 330 million people have hypertension in developed world and 640 million people have hypertension in developing world. World Health Organization (WHO) rates hypertension as one of the most important causes of premature death worldwide and the problem is growing. ${ }^{1}$

Hypertension is one of the major cardiovascular problems in Urban and suburban areas of Nepal. Unlike thought before, it is increasing among young population and in all social strata. Approximately one in five adults in urban areas of Nepal has hypertension. Majority of them are unaware and untreated. The prevalence of hypertension was $19.7 \%$ among the adults (18 years and more) in suburban areas of Nepal. Likewise, Awareness, treatment and control rates are very low. ${ }^{2}$

The key objective of the study was to identify the prevalence, awareness, treatment and control of hypertension among young population in Kathmandu.

\section{Methods}

It was a cross sectional study, descriptively analyzed on the basis of primary data collected on the one day screening programs conducted by Shahid Gangalal National Heart Center, Bansbari, Kathmandu in the shopping malls. The screening programs were conducted in two different malls, namely The City Center and The Civil Mall .They are grand shopping malls situated at the heart of Kathmandu. A screening team from Shahid Gangalal National Heart Center screened 261 people in the City Center and 225 participants in the Civil Mall.

Firstly, participants were explained about the program, registered and verbal concern was obtained. Then each participant was kept for rest at least five minutes in sitting position in the chair. The back was supported, both arms were at rest on chair and both feet were comfortably rested upon the floor. Blood pressure of each participant was measured by registered nurse by pretested sphygmomanometer and stethoscope. Blood pressures were measured to both arms and highest one was recorded. For those participants who identified as hypertensive, were reconfirmed.

Moreover, after measuring blood pressure, each participant was counseled accordingly. A team discussed on healthy diet, regular exercise, healthy lifestyle and importance of regular medicine in management of hypertension. Two thousand copies of an awareness pamphlet were also distributed to all the participants and visitors in the malls.
Blood pressure was further classified according to JNC-7 Classification of hypertension. Awareness of hypertension was defined as an awareness of the hypertensive participants about being hypertensive before examination of blood pressure. Treatment rate is defined as the rate of treatment among hypertensive participants. And, control rate is defined as the rate of hypertensive participants who maintained target blood pressure (ie < 140/90 $\mathrm{mmHg}$ ).

Finally, data are analyzed in SPSS16.0.

\section{Results}

\section{Brief Description of the participants}

In those two screening and awareness programs, 485 individuals were screened. Among the participants $346(67.1 \%)$ were male and $160(32.9 \%)$ female. They were staffs of malls, visitors, clients and others. Most of them were resides of Kathmandu and its periphery.

\section{Age distribution of the participants}

Majority of the participants of this study were young with the highest participation from age group $21-25$ yrs (27.08\%) followed by $15-20$ years (20.6\%), 26-30 yrs (17.9\%), 31-35 yrs $(11.3 \%)$ and so on. Mean age of the participants was $29.51 \pm$ SD 10.77 years.

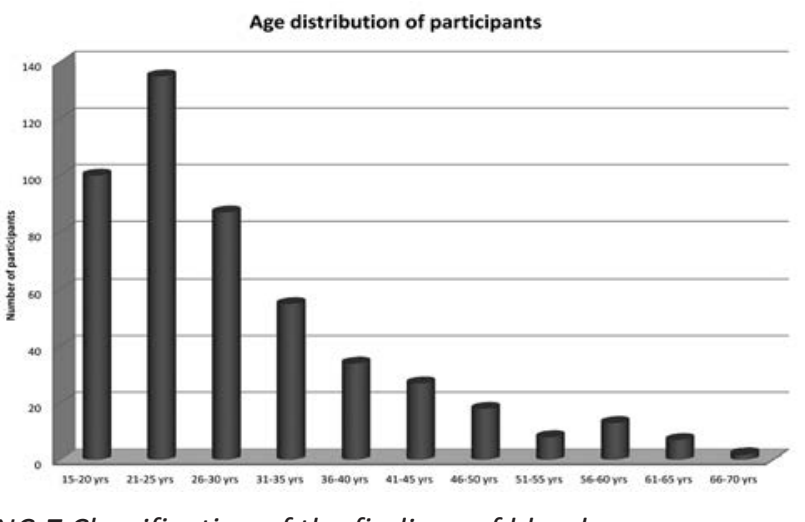

JNC-7 Classification of the findings of blood pressure

According to JNC-7 classification findings of blood pressure is described as below.

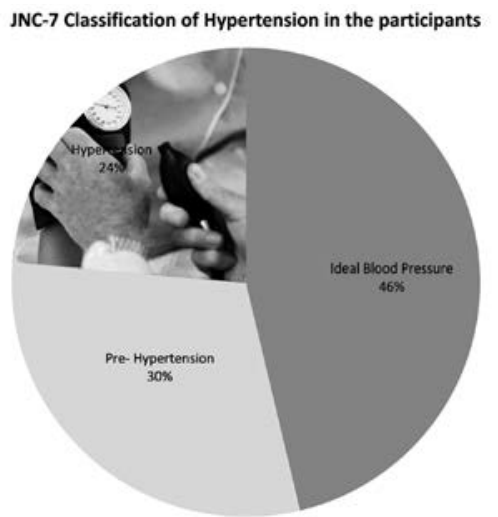


In this study, findings of blood pressure were classified according to JNC-7 classification. Ideal blood pressure was found among 225 (46.3\%) participants, Pre- Hypertension among 146 (30\%) participants and 115 participants were found to be hypertensive. So, the prevalence of hypertension was $23.7 \%$. Mean Systolic Blood Pressure was $112.03 \pm$ SD14.69mmHg and Mean Diastolic Blood Pressure was $75.09 \pm$ SD11.89 mmHg. Average mean blood pressure of the population was $87.41 \pm$ SD $12.28 \mathrm{mmHg}$.

\begin{tabular}{|c|c|c|c|c|c|c|c|}
\hline \multirow[t]{2}{*}{ Age Group } & \multicolumn{2}{|c|}{ Ideal Blood Pressure } & \multicolumn{2}{|c|}{ Pre-Hypertension } & \multicolumn{2}{|c|}{ Hypertension } & \multirow{2}{*}{$\begin{array}{c}\text { Total } \\
\text { Participants }\end{array}$} \\
\hline & Frequency & Percent & Frequency & Percent & Frequency & Percent & \\
\hline $15-20$ yrs & 56 & $56 \%$ & 38 & $38 \%$ & 6 & $6 \%$ & 100 \\
\hline $21-25$ yrs & 90 & $66.67 \%$ & 32 & $23.70 \%$ & 13 & $9.63 \%$ & 135 \\
\hline $26-30$ yrs & 38 & $43.67 \%$ & 27 & $31.03 \%$ & 22 & $25.29 \%$ & 87 \\
\hline $31-35$ yrs & 17 & $30.91 \%$ & 15 & $27.27 \%$ & 23 & $41.81 \%$ & 55 \\
\hline $36-40$ yrs & 11 & $32.35 \%$ & 13 & $38.24 \%$ & 10 & $29.41 \%$ & 34 \\
\hline $41-45$ yrs & 3 & $11.11 \%$ & 7 & $25.93 \%$ & 17 & $62.96 \%$ & 27 \\
\hline $46-50$ yrs & 4 & $22.22 \%$ & 7 & $38.89 \%$ & 7 & $38.89 \%$ & 18 \\
\hline $51-55$ yrs & 1 & $12.5 \%$ & 2 & $25 \%$ & 5 & $62.5 \%$ & 8 \\
\hline $56-60$ yrs & 4 & $30.77 \%$ & 3 & $23.08 \%$ & 6 & $46.15 \%$ & 13 \\
\hline $61-65$ yrs & 1 & $14.29 \%$ & 1 & $14.28 \%$ & 5 & $71.43 \%$ & 7 \\
\hline $66-70$ yrs & 0 & --------- & 1 & $50 \%$ & 1 & $50 \%$ & 2 \\
\hline Total & 225 & & 146 & & 115 & & 486 \\
\hline
\end{tabular}

\section{Age specific classification of hypertension}

The age specific prevalence of hypertension was lowest among 15-20 years age group and the highest among 61-65yrs age group. Highest prevalence of pre- hypertension was found in the age group 40-65 years, 36-40 years and equally in 15-20 years (38\%).

\section{Sex and Hypertension}

\begin{tabular}{|c|c|c|c|}
\hline Sex & Total Number & Hypertensive Subjects & Prevalence \\
\hline Male & 326 & 99 & $30.39 \%$ \\
\hline Female & 160 & 16 & $10 \%$ \\
\hline Total & 486 & 115 & $23.7 \%$ \\
\hline
\end{tabular}

The prevalence of hypertension was three times higher among men (30.39\%) in compare to women (10\%).

\section{Prevalence, awareness, treatment and control of hypertension (PATC)}

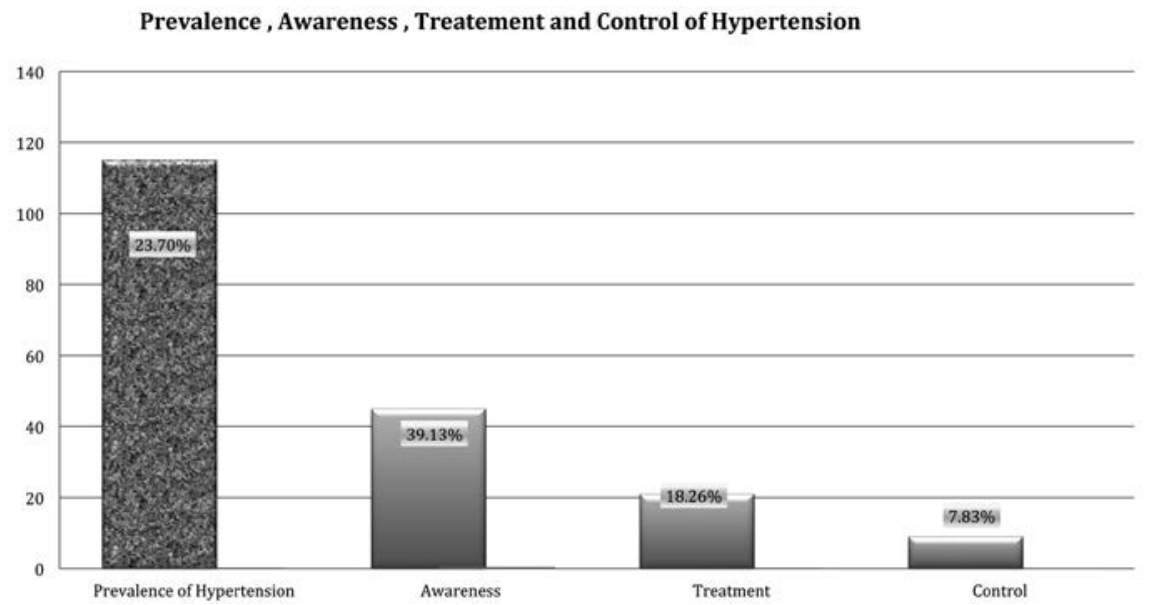

The prevalence of hypertension was $23.70 \%$. Among those 115 participants with hypertension, $39.13 \%$ were aware of the condition however only $18.26 \%$ of them were on treatment and only $7.83 \%$ had control over hypertension.

In summary, prevalence, awareness, treatment and control rates were $23.70 \%, 39.13 \%, 18.26 \%$ and $7.83 \%$ respectively. 


\section{Discussion}

Hypertension is a major global health problem and it is also a growing health problem for urban and sub-urban areas of Nepal. The prevalence of hypertension was $19.6 \%$ in sub urban areas of Nepal. ${ }^{1}$ It was $35.5 \%$ in Beijing, China. ${ }^{3}$ Almost 1 in 5 young adults have hypertension in the U.S. ${ }^{4}$ In our study, prevalence of hypertension was $23.7 \%$. It is of course higher than previous study of Nepal, despite the variation of the age of the participants in these two studies. In previous study, mean age of participants was $37.8 \pm$ 16.3 years while in our study it was $29.51 \pm 10.77$ years. Our prevalence was lesser than the prevalence in China. While comparing with recent Add Health Study in U.S., prevalence of this study was greater than previous study. It may be because of relatively smaller sample in this study.

In general, awareness, treatment and control rates are poor in Nepal. The awareness, treatment and control rates are $41.1 \%, 26 \%$ and 6\% in Nepal. ${ }^{2}$ Likewise it was $42.5 \%, 35.9 \%$ and $11.8 \%$ respectively in China. ${ }^{3}$ In our study, awareness rate was $39.13 \%$, treatment rate was $18.26 \%$ and control rate was $7.83 \%$.The rates of awareness and treatment were lesser than previous studies while control rate was improved in compare to previous study of Nepal. Yet, it was lesser in compare to China.
We found, prevalence of hypertension was three times higher among men in compare to women. Prevalence of hypertension among 15-20 yrs age group was 6\%. Most importantly $38 \%$ of them had pre-hypertension. More than two third of the hypertensive subjects in this study were less or equal to 40 years (64.35\%).

Hypertension is widely believed as an "old age" problem but the respective findings of this study highlight the fact that it may also be a "young age" problem as well.

The limitations to the study were relatively small sample size, it not a fully randomized sample and the sample was not taken from randomized population.

\section{Conclusion}

Though majority of participants were young, almost one out of four of them had hypertension and one in three of them were at risk of developing it. Hypertension is increasing even among young urban population of Nepal. Prevention, control and management of hypertension have immense importance in current scenario. Screening and awareness program like this could be a milestone for controlling cardiovascular disease as a whole in resource limited countries like Nepal.

\section{Reference}

1. World Heart Federation. Global Fact sheet. Cardiovascular Disease 2012 .

2. Sharma D, KC M, Rajbhandari S, et al. Study of Prevalence, Awareness and Control of Hypertension in a Suburban Area of Kathmandu, Nepal. Indian Heart Journal 2006.
3. Cai L, Liu A, Zhang L, et al. Prevalence, awareness, treatment and control of hypertension among adults in Beijin, China. Clinical exp hypertension 2012;34(1):45-52.

4. Harris KM. National Longitudinal Study of Adolescent Health (Add Health Study). Journal of Epidemiology 2011. 